\title{
PLACEBO RESPONSES IN AN ARTHRITIS TRIAL
}

BY

\author{
R. A. H. MORISON, A. WOODMANSEY, AND A. J. YOUNG \\ From the University Department of Clinical Medicine, General Infirmary, Leeds, and \\ Harrogate Royal Bath Hospital
}

Since the publication in this Journal of a description of the effects of placebos in rheumatoid conditions (Traut and Passerelli, 1957), there has been a growing literature on the subject of placebo responses, but little has appeared in print regarding such effects in arthritis.

During a recent intra-articular injection trial in which two steroid preparations and a placebo were compared, it became apparent that responses to the latter were frequent and well marked. It was decided, therefore, to make a parallel study of the whole question of placebo responses as these occurred during the trial.

The results of injection of the two steroids have already been reported; one paper dealt with the effects on rheumatoid arthritics (Chandler, Wright, and Hartfall, 1958) and the other with the effects on osteo-arthritics (Wright, Chandler, Morison, and Hartfall, 1960).

The present paper is concerned chiefly with a detailed examination of the responses to the placebo injections in the same trial. It also reports the results of a subsequent dummy tablet trial on the same group of patients. Finally, some of the implications of these findings as they apply to clinical trials are discussed.

\section{Material}

49 patients were included in the original trial, and of these, 10 dropped out for various reasons during the 18 months that the trial was in progress. The remaining 39 patients from whom results were complete, comprised 34 females and 5 males; 21 were osteo-arthritics, and the remaining eighteen rheumatoid arthritics, the knees being involved in every case. The age range was 29 to 76 years (mean 58.6). The two steroids used were hydrocortisone acetate, and hydrocortisone tertiary butyl acetate. The placebo consisted of the inert aqueous vehicle.

\section{Design of Injection Trial}

Every patient received three courses of injections into the affected knee, each course comprising four injections with an interval of 2 weeks between injections. There was a resting period of 2 months between courses, and the order in which courses were given was arranged so that every patient eventually received a course of each steroid and a course of the placebo.

Assessments for local pain and tenderness, range of joint movement, and walking time, were carried out at each visit. After careful consideration it was felt that walking-times would give the most useful single objective measurement by which clinical improvement or deterioration could be assessed. Patients were asked to walk a distance of 75 yards as quickly as possible while being timed by a stopwatch. The value taken was the mean of the four walking times which were measured fortnightly during the 2-month resting period following each complete injection course. These values were then expressed as percentages of the original walking time.

Alterations of less than \pm 10 per cent. were classified as "unchanged", while decreases or increases of more than 10 per cent. were classified as "improvement" or "deterioration" respectively. Throughout this article the values of these walking times are referred to as "findings".

Patients were given two opportunities to express their opinion as to the value of the three injection courses. The first occasion was at the time of taking the psychological history, i.e. within a few weeks of completing all three courses. They were questioned again some 6 months later at the time of the second psychological interview so that the consistency of their replies was ascertained.

The patients' answers were recorded under the heading of "claims", and classified as "unchanged", 
"improved", and "deteriorated". In all cases in which a patient's two replies showed inconsistency, the result was entered as "unchanged".

\section{Results of Injection Trial}

While it was found that there were more placebo responses amongst rheumatoid arthritics than amongst osteo-arthritics, this difference was not statistically significant and therefore both groups are considered together in this study. Furthermore, as the two forms of hydrocortisone injected showed no significant difference in their effects on the walking time, they have been taken together and the mean values recorded, and these results have been compared with those from injections of "placebo". Thus there were 78 courses of steroid injections and 39 courses of placebo injections, a total of 117 courses, comprising 468 actual injections.

Comparison between Steroid and Placebo Injections. Table I shows these results and, as there were two steroid courses and only one placebo course for each patient, the percentages are given in brackets for comparison. It should be noted that findings and claims do not necessarily refer to the same actual patients. For example, in line 1 (col. 4) of the Table, seven patients were found to have improved with placebo injections, but these seven did not all come from the sixteen shown in line 1 (col. 2) as claiming improvement. The same holds good for the deteriorations, in which many claims were not substantiated by findings, and conversely several who were found to have deteriorated stated that they were unchanged, and one patient actually claimed improvement. In this respect it should be pointed out that factors other than walking time might well have affected patients and so influenced their claims.

It will be seen that deteriorations are of a similar

TABLE I

COMPARISON OF CLAIMS AND FINDINGS WITH STEROID AND PLACEBO INJECTIONS

\begin{tabular}{|c|c|c|c|c|c|}
\hline \multirow{2}{*}{ Result } & & \multicolumn{2}{|c|}{ Claims } & \multicolumn{2}{|c|}{ Findings } \\
\hline & & $\begin{array}{c}\text { Steroids } \\
\text { (Mean of 2) }\end{array}$ & Placebo & $\begin{array}{c}\text { Steroids } \\
\text { (Mean of 2) }\end{array}$ & Placebo \\
\hline Improved & .. & $20.5(53 \%)$ & $16(41 \%)$ & $9.5(25 \%)$ & $7(18 \%)$ \\
\hline Deteriorated & $\cdots$ & $4(10 \%)$ & $3(8 \%)$ & $2.5 \quad(6 \%)$ & $(5 \%)$ \\
\hline Unchanged & . & $14 \cdot 5(37 \%)$ & $20(51 \%)$ & $27 \quad(69 \%)$ & $30(77 \%)$ \\
\hline Total & . & $39(100 \%)$ & $39(100 \%)$ & $39(100 \%)$ & $39(100 \%)$ \\
\hline
\end{tabular}

$\chi^{2}=1.57 ; 0.5>P>0.3 \quad \chi^{2}=0.6 ; 0.8>P>0.7$ order throughout. Claims for improvement show $\frac{0}{\bar{\sigma}}$ 53 per cent. for steroids and 41 per cent. for placebo; actual findings for improvement, however, rate 25 per cent. for steroids and 18 per cent. for placebo. o? Although both claims and findings show higher $\vec{\Rightarrow}$ percentages for steroids than placebo, these differ- $\stackrel{\mathscr{P}}{\rightarrow}$ ences do not attain statistical significance in this? relatively small sample.

Effect of Order of Courses.-It has been claimed by Fearnley, Lackner, Meanock, and Bywaters $\bigcirc$ (1956) that the order in which courses are given कै has a direct bearing on the results. Using hydro- $\overrightarrow{0}$ cortisone and procaine courses in a controlled intraarticular trial, these workers found that on objective $\vec{\omega}$ assessment the first course conferred greater benefit irrespective of the nature of the substance injected. Some evidence in support of this principle may be $N$ adduced from our results below.

Fig. 1 (opposite) shows both claims and findings $\vec{v}$ with the number of improvements and deteriorations $\omega$ for each course. Throughout this histogram steroid $\frac{}{2}$ and placebo results are summated, as it is only the $\overrightarrow{-}$ order of the courses that is under consideration. In Fig. 1A it will be seen that the number of claims $ه$ stating that patients were unchanged remains almost $\vec{\bullet}$ constant (16:16:17), while the claims for improve? ment for the second and third courses does net differ greatly from those for the first coure $(21: 17: 19)$. With regard to claims for deterioration these total only eleven for all three courses, those for the second course being highest $(2: 6: 3)$.

Fig. 1B deals with actual findings, and it is here that our results support the work of Fearnley and $\bar{O}$ others (1956). The histogram shows that the number of patients remaining unchanged is almost twice as high for the second and third courses as for the first course $(17: 32: 32)$. The number of $\frac{\varrho}{2}$ objective improvements, however, following the $\frac{0}{\sigma}$ first course far exceeds the sum of the improvements for the second and third courses together (19:4:5). The number of deteriorations remains almost $₹$ constant at a low figure $(2: 3: 2)$. It is interesting 0 to note that while the findings for improvement following the first course almost equal the claims (20:21), there is no such corresponding agreement between the claims and the findings of improvement $\sigma$ for the second and third courses. These discrepan- N cies will be referred to in the Discussion.

\section{Design of Tablet Trial}

By the time all patients had completed their $\stackrel{\Phi}{\oplus}$ three injection courses many of the foregoing results had come to light, and it was thought that a further trial using placebo tablets only might serve to 
[A] CLAIMS

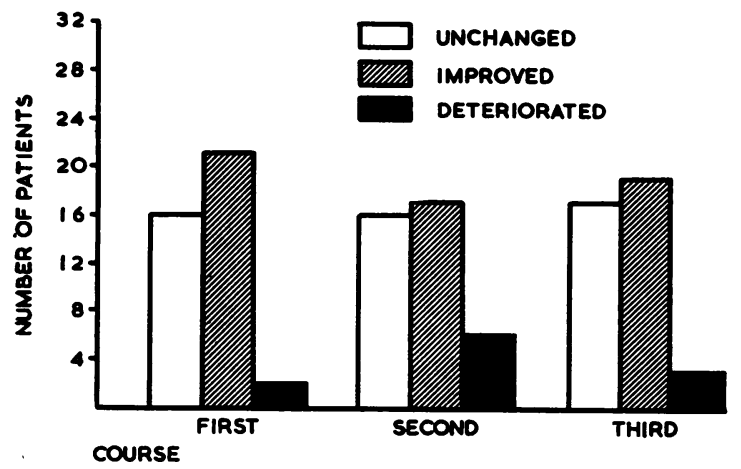

[B] FINDINGS

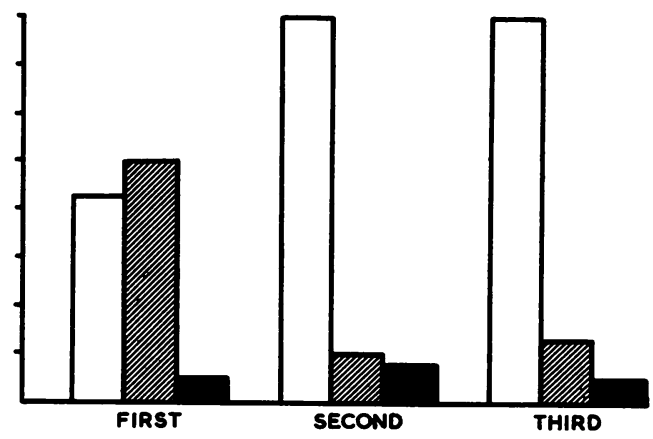

Fig. 1.-Effect of order of courses-steroids and placebos taken together in each case.

elucidate certain aspects of the problem. Two particular points on which further information was sought were whether placebo responses were consistently produced by certain patients, and whether these patients had any marked psychological characteristics.

All patients were given a week's supply of dummy tablets which contained starch, chalk, and a trace of sodium sulphate to give some taste. The tablets were issued on a normal hospital prescription and obtained from the dispensary in the usual manner. The instructions were simply "one three times daily after meals".

Patients were asked to return a form on completion of the week's course, on which they were asked to mark whether the tablets had in their opinion produced improvement, no change, or a deterioration of their condition. In addition, they were asked to note on the obverse, " . . . any other effects caused by the tablets (i.e. giddiness, sickness, tinglings, etc.)". One patient failed to complete the tablet trial, leaving 38 for whom results are available.

\section{Results of Tablet Trial}

Ten patients claimed improvement with dummy tablets, twelve claimed deterioration, and sixteen indicated that they were unchanged. With regard to reports on side-effects, many went far beyond any suggestions made on the form, claiming such things as headaches, impaired vision, burning sensations, and backache. One patient stated: "These tablets made my head fuzzy . . . and my tongue black". Altogether sixteen patients reported side-effects (42 per cent.).

\section{Combined Results of the Two Trials}

Table II sets out the combined results of the two trials in so far as placebo substances are concerned (the results of steroid therapy in the injection trial have been shown in Table I). It will be seen that there are more improvements after placebo injections than after placebo tablets. These results are in keeping with work by others in this field (Traut and Passerelli, 1957), who found that more than half the patients who were resistant to placebo tablets, responded to placebo injections. We also found that while only three claims of deterioration were made against placebo injections, there were twelve claims of deterioration against the tablets. This difference may be due to the method by which the placebo is given (i.e. injection as opposed to oral administration), and it is significant at the 3 per cent. level.

TABLE II

COMBINED RESULTS OF TRIALS 1 AND 2

\begin{tabular}{|c|c|c|c|c|}
\hline \multicolumn{3}{|c|}{ Patients' Claims } & Placebo Injections & Placebo Tablets \\
\hline $\begin{array}{l}\text { Better } \\
\text { Worse } \\
\text { Unchanged }\end{array}$ & $\begin{array}{l}\cdots \\
\cdots \\
\cdots\end{array}$ & $\begin{array}{l}\cdots \\
\cdots \\
\cdots\end{array}$ & $\begin{array}{rr}16 & (41 \%) \\
3 & (8 \%) \\
20 & (51 \%)\end{array}$ & $\begin{array}{l}10(26 \%) \\
12(32 \%) \\
16(42 \%)\end{array}$ \\
\hline Total & $\ldots$ & & $39(100 \%)$ & $38(100 \%)$ \\
\hline
\end{tabular}

Difference in regard to worse patients is significant (Critical Ratio $=2.22 P=0.03$ )

We come now to the interesting relationship between placebo-response and claims of side-effects with the dummy tablets. All sixteen patients who claimed side-effects from the inert tablets either showed placebo response in the tablet trial, or had previously shown placebo response in the injection trial. Not one of the eleven patients who were 
consistent non-responders in both trials reported side-effects with the dummy tablets. This finding, which is highly significant $(P<0.01)$, is shown in Table III.

TABLE III

RELATIONSHIP BETWEEN PLACEBO RESPONDERS AND SIDE-EFFECTS

\begin{tabular}{|c|c|c|}
\hline Category & Total & $\begin{array}{l}\text { No. Showing } \\
\text { Side-Effects }\end{array}$ \\
\hline 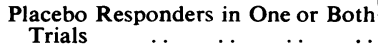 & 27 & 16 \\
\hline Constant Non-responders $\ldots \quad \ldots$ & 11 & 0 \\
\hline
\end{tabular}
$\chi^{2}=6 \cdot 65 ; P<0 \cdot 01$

Consistency of Placebo Responses. - The degree of consistency may be judged from the fact that, dealing with placebo injections and tablets, there was one patient who claimed to be worse in both trials, four claimed to be better in both, and eleven consistently stated that they were unchanged. The remaining 22 patients were inconsistent in their placebo claims.

Of the eighteen who showed placebo-response in the injection trial, twelve continued to show such response to placebo tablets. The 27 patients shown in Table III as placebo-responders in one or both trials constitute 71 per cent. of the total.

Relationship between Frequency of Claims and Side-Effects. - It will be recalled that patients could make one claim for improvement or deterioration with each of the three injection courses, and one further such claim for the course of placebo tablets. Thus we have four occasions on which the patient either claimed or did not claim. It should be noted that all claims for improvement or deterioration with steroids or placebo are included.

It was found that no patient making less than two claims reported side-effects with placebo tablets, and it can be seen from the histogram in Fig. 2 that there were nine such cases (three made no claim and six made only one claim). Of the twelve patients who made two claims, three reported side-effects. When three claims were made, eight out of ten patients reported side-effects. Finally, in the group making the maximum of four claims, five out of seven reported side-effects with dummy tablets. Thus it appears from Fig. 2 that the frequency of claims follows closely the curve of normal distribution. Side-effects do not occur at all in the first two groups, and only to the extent of 25 per cent. in the middle group, but the frequency is much higher (70-80 per cent.) in the remaining two groups.

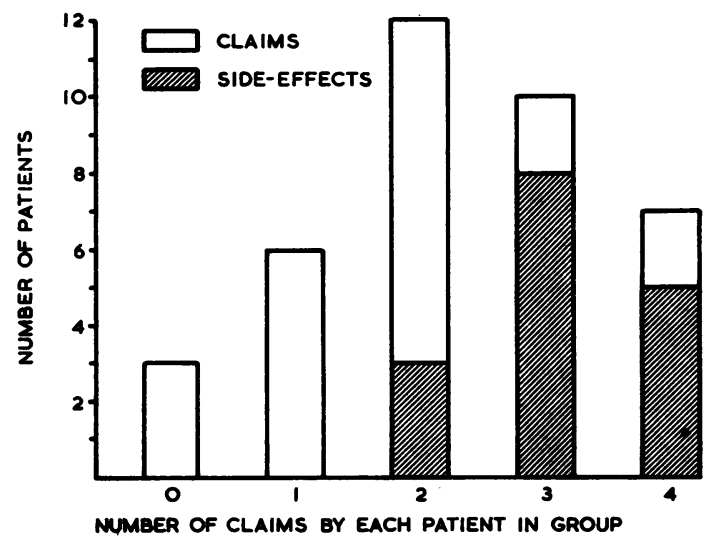

Fig. 2.-Relationship of claims to side-effects.

\section{Psychological Investigations}

A considerable part of our investigations into placebo responses was concerned with the psychological aspects of the problem. Although the bulk of these findings will form the basis of a further paper, some of the more important results will now be considered briefly.

Every patient was given two separate psychog logical interviews during which a special histor was taken with regard to emotional stress as a aetiological factor in the arthritis.

Factors such as stress, bereavement, and marital separation were considered in so far as their occurrence coincided with the time of onset. It was found that such psychological stress occurred three times more often in the group of placebo responders than it did in those who were consistent nonresponders. This finding was significant at the 2 per cent. level.

All patients were given questionnaires to complete at each of their two interviews. The first of these was the Maudsley Personality Inventory (M.P.I.), which was subsequently scored for neuroticism (higher scores indicating neurotic tendencies). The M.P.I. was also scored on the extroversion/introversion scale (low scores indicating introversion, high scores extroversion). It was found that patients claiming improvement with placebos (positive responders), showed a significant trend towards introversion $(P<0.03)$ and a highly significant degree of neuroticism $(P<0.01)$.

The other questionnaire, the Bernreuter Personality Inventory, confirmed many of these findings and also gave a score for social dominance. It was found that patients claiming deterioration with placebos (negative responders) scored significantly higher on the scale of social dominance, as com- 
pared with those claiming improvement or reporting no change $(P<0.05)$.

These findings are summarized in Table IV.

TABLE IV

SUMMARY OF PSYCHOLOGICAL FINDINGS

\begin{tabular}{c|l|c}
\hline Category & Psychological Characteristics & Significance \\
\hline $\begin{array}{c}\text { Pll } \\
\text { Placebo } \\
\text { Responders }\end{array}$ & $\begin{array}{c}\text { Major psychological stress in } \\
\text { relation to aetiology }\end{array}$ & $P<0.02$ \\
\cline { 2 - 3 } $\begin{array}{c}\text { Positive } \\
\text { Placebo } \\
\text { Responders }\end{array}$ & Intronersion to report side-effects & $P<0.01$ \\
\hline $\begin{array}{c}\text { Negative } \\
\text { Placebo } \\
\text { Responders }\end{array}$ & Social Dominance & $P<0.03$ \\
\hline
\end{tabular}

\section{Discussion}

In recent years many placebo trials have been carried out on groups of healthy subjects, such as nurses and students, by different teams of workers in Great Britain, e.g. Joyce (1959) and Knowles and Lucas (1960). Their publications, together with the review of the literature by Trouton (1957), provide a useful background to placebo studies.

In America, the work of Wolf and Pinsky (1954) and of Lasagna, Mosteller, von Felsinger, and Beecher (1954), with that of Beecher (1955), drew attention to the importance of placebos and their side-effects. The excellent historical review by Shapiro (1960) gives some idea of how placebo effects have dominated therapeutics since antiquity, and yet until the fifth decade of this century only sporadic publications on the subject have appeared. The urgent necessity for further work on this subject has been emphasized by a recent annotation in the British Medical Journal (1961).

In the present paper, reference to Table I shows that the percentage claims for deterioration are almost the same after the placebo injections as after steroids (8 as opposed to 10 per cent.). Similarly, with the findings in which 5 per cent. show actual deterioration after placebo and 6 per cent. after steroids. The difference is negligible and suggests that such deteriorations may be due in part to natural exacerbations of the disease, rather than to the steroid injections. It has been shown, however, that repeated injections of steroids into rheumatoid arthritic knee joints cause significant radiological deterioration (Chandler and Wright, 1958). One must also make due allowances for natural remissions when considering the claims for improvement, although such cannot be specified exactly. In any case the 53 per cent. improvement claim after steroid injections is hardly impressive in view of the 41 per cent. improvement claim after placebo injections.

Perhaps more surprising are the actual findings (Table I, cols 3 and 4), which show that the percentage of objective improvement after placebo injections amounts to nearly three-quarters of that after steroids. It would appear from this finding that, with repeated intra-articular injections of steroids, much of the reputed therapeutic benefit is in fact placebo effect. The only significant difference between steroid and placebo in the entire trial was the transient improvement in relief of pain 2 weeks after one of the steroid preparations which has already been reported (Wright and others, 1960).

In the section dealing with the order of courses it was noted that the number of improvement claims varied only slightly between the three courses (Fig. 1A). In contrast, the objective findings (Fig. 1B) show a remarkable drop in the number of improvements following the second and third courses, as compared with those following the first course. This suggests that the enthusiasm which develops amongst the staff at the outset of any new trial is subtly but effectively communicated to the patients, and this optimism is liable to give rise to marked placebo effects. The extravagant claims so frequently made for new drugs which later prove of little value is due in part to failure to allow for this enhanced placebo effect. It would, therefore, appear highly desirable in future to conduct controlled trials in two or more phases, and to regard the results of the first phase as tentative and awaiting confirmation.

In the comparison between the injection trial and the tablet trial, we are inclined to think that the ratio of $3: 2$ which favours improvements with injections, and the more striking fact that four times as many patients claim deterioration with tablets, are due to the different methods of administrating the placebos. In the case of the injection courses, the whole paraphernalia of the aseptic ritual can hardly fail to impress suggestable patients, whereas the mere prescribing of tablets is surrounded by no such aura.

Joyce's view that placebo responders and nonresponders form a continuum is amply borne out by our findings on the distribution of claims. The curve is that of normal frequency distribution slightly skewed to the right. The constant nonresponders fall to the left and show no side-effects. The largest group are centrally placed and may be termed occasional responders who sometimes show side-effects. To the right of the curve lie the regular responders who nearly all show side-effects. It 
would appear that while accurate prediction of placebo responders is not possible, the general distribution can be forecast, and in our group it was as follows: 29 per cent. non-responders, 37 per cent. occasional responders, and 34 per cent. regular responders.

In the psychological approach made in this study the findings in respect of association of stress with the onset of the disease were not unexpected in view of previous published work on this subject, e.g. Johnson, Shapiro, and Alexander (1947) and Hartfall (1954). The idea that placebo responders are hysterical types is not substantiated by the facts, otherwise those showing the combination of neuroticism with extroversion would be placebo responders, whereas the responders were in fact mostly neurotic introverts. It should be noted that the word neurotic in this sense refers to the trait as measured on the Maudsley Personality Inventory scale which Eysenck (1959) equates with autonomic lability. It does not necessarily indicate that such patients require psychiatric treatment.

In concluding this contribution to a difficult subject, we would emphasize that the foregoing study is based on observations made during an actual clinical trial, and as the reactions of patients suffering from a chronic disease are likely to differ considerably from those of healthy young normal subjects, this detailed report should be of interest to those engaged in planning future trials. The famous witticism uttered by Trousseau in 1833, that you should treat as many patients as possible with new drugs while they have the power to heal, is still applicable to the field of thcrapeutics. Indeed, it is likely to remain so, as it appears that placebo responders, like the poor, are with us always.

\section{Summary}

An injection trial, using two steroid drugs and a placebo, was carried out on a group of 39 patients, all of whom had rheumatoid or osteo-arthritis affecting the knees. This paper analyses the results of the placebo injections, together with those of a further trial, using orally-administered placebo tablets. 25 per cent. showed objective improvement with steroid injections and 18 per cent. with placebo injections, a difference which is not statistically significant with small numbers.

The order in which injection courses were given was found to have a marked effect on the results, the first course producing far greater objective improvement than either of the subsequent courses irrespective of the substance administered.

In the tablet trial, fewer claimed improvement with placebo, and more claimed deterioration than in the injection trial. The discrepancies between claims for dummy tablets and placebo injections are discussed. Altogether 71 per cent. of the patients showed a placebo response of some kind.

Placebo responders were found to show higher scores for neuroticism and introversion. Negative responders showed higher scores for social dominance. It is shown that placebo responders form a continuum coincident with a curve of normal distribution, and constant non-responders do not show side-effects. A suggestion is made regarding the conduct of clinical trials.

We are much indebted to Prof. S. J. Hartfall for his continued interest and encouragement in this work. We should also like to express our thanks to Prof. G. R. Hargreaves for allowing one of us (A.J.Y.), to devote considerable time to the psychological aspects of this study.

Finally, we wish to thank Sister P. R. Benson and her nursing staff for their co-operation.

\section{REFERENCES}

Beecher, H. K. (1955). J. Amer. med. Ass., 159, 1602. Brit. med. J. (1961). Annotation, 1, 43.

Chandler, G. N., and Wright, V. (1958). Lancet, 2, 661 ,-- , and Hartfall, S. J. (1958). Ibid., 2, 659.

Eysenck, H. J. (1959). "Manual of the Maudsle 8 Personality Inventory." University of Londo Press, London.

Fearnley, G. R., Lackner, R., Meanock, R. I., an Bywaters, E. G. L. (1956). Ann. rheum. Dis., $15,134$.

Hartfall, S. J. (1954). Practitioner, 172, 29.

Johnson, A., Shapiro, L. B., and Alexander, F. (1947). Psychosom. Med., 9, 295.

Joyce, C. R. B. (1959). Brit. J. Pharmacol., 14, 512.

Knowles, J. B., and Lucas, C. J. (1960). J. ment. Sci., 106, 231.

Lasagna, L., Mosteller, F., von Felsinger, J. M., and Beecher, H. K. (1954). Amer. J. Med., 16, 770.

Shapiro, A. K. (1960). Behavioral Sci., 5, 109.

Traut, E. F., and Passarelli, E. W. (1957). Ann. rheum. Dis., 16, 18.

Trouton, D. S. (1957). J. ment. Sci, 103, 344.

Wolf, S., and Pinsky, R. H. (1954). J. Amer. med. Ass., $155,339$.

Wright, V., Chandler, G. N., Morison, R. A. H., and Hartfall, S. J. (1960). Ann. rheum. Dis., 19, 257.

Réactions aux placebos (produits factices, témoins) dans un essai thérapeutique de l'arthrite

RÉSUMÉ

Un essai thérapeutique, en usant deux substances $\underset{\gamma}{ }$ stéroïdes et un placebo en injections, fut effectué chez 0 39 malades atteints d'arthrite rhumatismale ou d'ostéoarthrite avec implication du genou. Dans ce travail, \& on analyse les résultats obtenus avec des injections de placebo, ainsi que les résultats obtenus dans un autre travail, où la substance factice fut administrée sous forme de comprimés. Vingt-cinq pour cent des malades 
accusèrent une amélioration objective après des injections des stéroïdes et $18 \%$ d'entre eux furent améliorés après des injections de placebo; cette différence, le groupe étant petit, est statistiquement insignifiante.

L'ordre dans lequel ces séries d'injections furent administrées eut un effet remarquable sur les résultats, et la première série produisit une amélioration objective très supérieure à celle obtenue avec les séries suivantes, indépendamment de la substance injectée.

Dans l'essai effectué avec des comprimés, il y eut moins de malades améliorés et plus d'empirés avec le placebo, que dans l'essai comportant des injections. On discute les causes de cette divergence entre les effets des comprimés factices et ceux des injections factices. En tout, $71 \%$ des malades réagirent d'une manière quelconque au placebo.

On trouve que les malades qui réagissent au placebo ont un indice plus élevé d'introversion et de névrose. Ceux qui réagissent négativement indiquent une tendance à la dominance sociale. On montre que ceux qui réagissent au placebo représentent graphiquement un continuum coincidant avec la courbe de distribution normale. On fait une suggestion concernant la manière de conduire les essais cliniques.

\section{Reacciones a substancias farmacológicamente inactivas (placebos) en artritis \\ Sumario}

Se realizó un estudio terapéutico, utilizando dos esteroides y un placebo inyectados, en un grupo de 39 enfermos con artritis reumatoide $u$ osteoartritis implicando la rodilla. En esta publicación se analizan los resultados obtenidos con las inyecciones de placebo así como los resultados obtenidos en un otro estudio en el cual el placebo fué administrado en forma de comprimidos. Un 25 por ciento mostró una mejoría objetiva con las inyecciones de esteroides y un 18 por ciento con inyecciones de placebo; esta diferencia, siendo el grupo pequeño, no es estadísticamente significativa.

El orden de administración de la series de inyecciones tuvo un marcado efecto en los resultados, produciendo la primera serie una mejoría objetiva muy superior a la obtenida con las series subsecuentes, cualquiera fuera la substancia inyectada.

En la prueba realizada con los comprimidos, menos enfermos acusaron mejoría y más empeoramiento con el placebo, que en la prueba con las inyecciones. Se discuten las razones de esta divergencia entre efectos de falsos comprimidos y los de falsas inyecciones. En total, un $71 \%$ de los enfermos mostraron reacción de alguna clase al placebo.

Se comprobó que los enfermos que responden al placebo tienen más indicios de introversion y de neurosis. Aquellos que responden negativamente tienden a ser socialmente dominantes. Representados estadísticamente, las personas que responden al placebo forman un contínuo coincidente con una curva de distribución normal. Se presenta una sugerencia referente a la forma de conducir pruebas clínicas. 